\title{
HIF-P4H-2 inhibition enhances intestinal fructose metabolism and induces thermogenesis protecting against NAFLD
}

\author{
Anna Laitakari ${ }^{1}$ • Joona Tapio ${ }^{1} \cdot$ Kari A. Mäkelä ${ }^{2} \cdot$ Karl-Heinz Herzig $^{2,3} \cdot$ Franziska Dengler $^{4} \cdot$ Helena Gylling $^{5}$. \\ Gail Walkinshaw $^{6} \cdot$ Johanna Myllyharju $^{1} \cdot$ Elitsa Y. Dimova ${ }^{1} \cdot$ Raisa Serpi $^{1} \cdot$ Peppi Koivunen $^{1}$
}

Received: 25 November 2019 / Revised: 6 March 2020 / Accepted: 24 March 2020 / Published online: 15 April 2020

(C) The Author(s) 2020

\begin{abstract}
Non-alcoholic fatty liver disease (NAFLD) parallels the global obesity epidemic with unmet therapeutic needs. We investigated whether inhibition of hypoxia-inducible factor prolyl 4-hydroxylase-2 (HIF-P4H-2), a key cellular oxygen sensor whose inhibition stabilizes HIF, would protect from NAFLD by subjecting HIF-P4H-2-deficient $\left(H i f-p 4 h-2^{g t / g t}\right)$ mice to a high-fat, high-

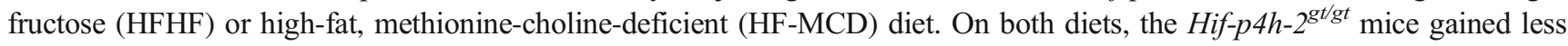
weight and had less white adipose tissue (WAT) and its inflammation, lower serum cholesterol levels, and lighter livers with less steatosis and lower serum ALT levels than the wild type (WT). The intake of fructose in majority of the Hif-p $4 h-2^{\text {gt/gt }}$ tissues, including the liver, was 15-35\% less than in the WT. We found upregulation of the key fructose transporter and metabolizing enzyme mRNAs, Slc2a2, Khka, and Khkc, and higher ketohexokinase activity in the Hif-p4h-2 ${ }^{g t g t}$ small intestine relative to the WT, suggesting enhanced metabolism of fructose in the former. On the HF-MCD diet, the Hif-p $4 h-2^{\text {gttgt }}$ mice showed more browning of the WAT and increased thermogenesis. A pharmacological pan-HIF-P4H inhibitor protected WT mice on both diets against obesity, metabolic dysfunction, and liver damage. These data suggest that HIF-P4H-2 inhibition could be studied as a novel, comprehensive treatment strategy for NAFLD.
\end{abstract}

\section{Key messages}

- HIF-P4H-2 inhibition enhances intestinal fructose metabolism protecting the liver.

- HIF-P4H-2 inhibition downregulates hepatic lipogenesis.

- Induced browning of WAT and increased thermogenesis can also mediate protection.

- HIF-P4H-2 inhibition offers a novel, comprehensive treatment strategy for NAFLD.

Keywords Fructose $\cdot$ HIF $\cdot$ Hypoxia response $\cdot$ Metabolism $\cdot$ NAFLD

Electronic supplementary material The online version of this article (https://doi.org/10.1007/s00109-020-01903-0) contains supplementary material, which is available to authorized users.

Peppi Koivunen

peppi.koivunen@oulu.fi

1 Biocenter Oulu, Faculty of Biochemistry and Molecular Medicine, Oulu Center for Cell-Matrix Research, University of Oulu, Aapistie 7C, FIN-90014 Oulu, Finland

2 Research Unit of Biomedicine, Biocenter Oulu, Medical Research Center and University Hospital, Oulu, Finland
3 Department of Gastroenterology and Metabolism, Poznan University of Medical Sciences, Poznan, Poland

4 University of Leipzig, Leipzig, Germany

5 Internal Medicine, University of Helsinki and Helsinki University Hospital, 00029 HUS Helsinki, Finland

6 FibroGen, Inc., San Francisco, CA, USA 


\section{Introduction}

The prevalence of non-alcoholic fatty liver disease (NAFLD) is constantly increasing, currently affecting a quarter of people worldwide [1]. It is considered the hepatic manifestation of metabolic syndrome, strongly linked to obesity and insulin resistance (IR), which further predisposes for diabetes and cardiovascular diseases [2]. NAFLD is characterized by hepatic triglyceride accumulation and if untreated, can lead to steatohepatitis (NASH), cirrhosis, and hepatocellular carcinoma (HCC) [1]. Western diet, rich in saturated fat and carbohydrates, especially fructose, is considered to be one of the major causes of the NAFLD epidemic [3]. No effective cure is currently available [4].

A decrease in oxygen availability activates a survival mechanism called the hypoxia response [5-7]. Hypoxiainducible factor (HIF) functions as the major regulator of oxygen homeostasis, and HIF prolyl 4-hydroxylases (HIFP4Hs/PHDs/EglNs), especially HIF-P4H-2, are oxygen sensors that target $\mathrm{HIF} \alpha$ for degradation under normoxia $[5,8]$. Under hypoxia, the oxygen-dependent hydroxylation is compromised [9], allowing HIF to form a transcriptionally active $\alpha \beta$-dimer and upregulate $>300$ genes. These genes increase oxygen availability by inducing erythropoiesis and angiogenesis, and also reduce its demand via regulation of energy metabolism by reducing oxidative phosphorylation and inducing non-oxygendemanding glycolysis [5-7].

The first-in-class small-molecule HIF-P4H inhibitor that activates the hypoxia response has been approved for treatment of renal anemia and several others are in clinical trials $[10,11]$. Recent data suggest that besides anemia, HIF-P4H inhibition and hypoxia are powerful tools for promoting metabolic health $[10,12-17]$. We have previously shown that genetic HIF-P4H-2 deficiency protects the Hif-p $4 h-2^{g t / g t}$ mice against metabolic disorder-related hepatic steatosis and chemically induced HCC [14, 18], and against alcoholic liver disease (ALD) by downregulating hepatic lipogenesis and improving the elimination of harmful ethanol metabolites and reactive oxygen species [19]. Treatment of wild-type (WT) mice with a pan-HIF-P4H inhibitor FG-4497 phenocopied the protection against ALD [19]. However, the role of HIFP4H-2 in NAFLD has not been studied systemically before. We therefore subjected the Hif-p $4 h-2^{g t / g t}$ mice, and FG-4497-treated WT mice, to two diet-induced rodent NAFLD models: a high-fat, high-fructose (HFHF) diet [20] and a methionine-choline-deficient high-fat diet (HF-MCD) [21] that mimic the human disease. The HFMCD can additionally lead to NASH [22]. Our data show significantly less steatosis and liver damage in the Hif$p 4 h-2^{g t / g t}$ mice compared with the WT. Treatment with FG-4497 phenocopied most of these effects.

\section{Materials and methods}

\section{Animal experiments}

Animal experiments were performed according to protocols approved by the National Animal Experiment Board of Finland (ESAVI-6154, ESAVI-8179). Hif-p4h-2 ${ }^{g t / g t}$ mice were generated as previously described [23]. Five-month-old Hif-p $4 h-2^{g t / g t}$ and WT males were fed a $30 \%(\mathrm{w} / \mathrm{v})$ fructose solution for drinking water combined with a high-fat, modified Surwit diet with added cholesterol (HFHF diet, D09061703, 58\% kcal fat) for 8 weeks. Six-month-old and 2-month-old Hif-p $4 h-2^{\text {gt/gt }}$ and WT females were fed a highfat, choline-deficient diet with $0.1 \%$ methionine (HF-MCD diet, A06071309, 45\% kcal fat) for 7 weeks, and the 2month-old mice were studied with an automated home cage phenotyping system (PhenoMaster, TSE Systems) for the last week. For the pharmacological studies, 8-month-old WT females (Hif-p $4 h-2^{\text {gt/gt }}$ littermates) were fed the HFHF diet for 6 weeks and 4-month-old WT females (C57BL/6JRccHsd, Envigo) the HF-MCD diet for 3 weeks and given thrice a week orally $60 \mathrm{mg} / \mathrm{kg}$ FG-4497 (FibroGen, Inc., USA) or vehicle.

Further methods are described in the supplementary material.

\section{Results}

\section{HIF-P4H-2-deficient mice were protected from fructose diet-induced weight gain, but the diet did not induce NAFLD}

Hif-p $4 h-2^{g t / g t}$ mice and their WT littermates were fed a standard rodent diet with a $30 \%$ fructose solution for 16 weeks. Although the daily intake of the fructose solution was similar between the genotypes (Fig. S1a), the Hif-p $4 h-2^{\text {gt/gt }}$ mice had a $\sim 20 \%$ lower body weight than the WT at sacrifice, had gained less weight during the diet, and had $>50 \%$ less gonadal white adipose tissue (WAT) (Fig. S1b-d). The Hif-p4h-2 ${ }^{g t / g t}$ mice also showed a slight trend towards better glucose tolerance compared with the WT (Fig. S1e). The Hif-p $4 h-2^{g t / g t}$ livers were $21 \%$ lighter than the WT livers (Fig. S1f), suggesting more fructose-induced hepatic steatosis in the WT, since no baseline difference exits between the genotypes [14]. However, the diet only induced visible steatosis and increased the serum alanine aminotransferase (ALT) levels in a few WT mice, and no liver inflammation in either genotype (Fig. S1g-i), thus not being potent enough to induce NAFLD. Hence, we next combined the $30 \%$ fructose solution with a high-fat diet (HFHF) to better mimic Western diet. 


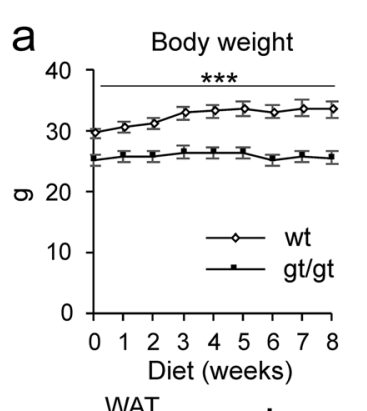

b Body weight
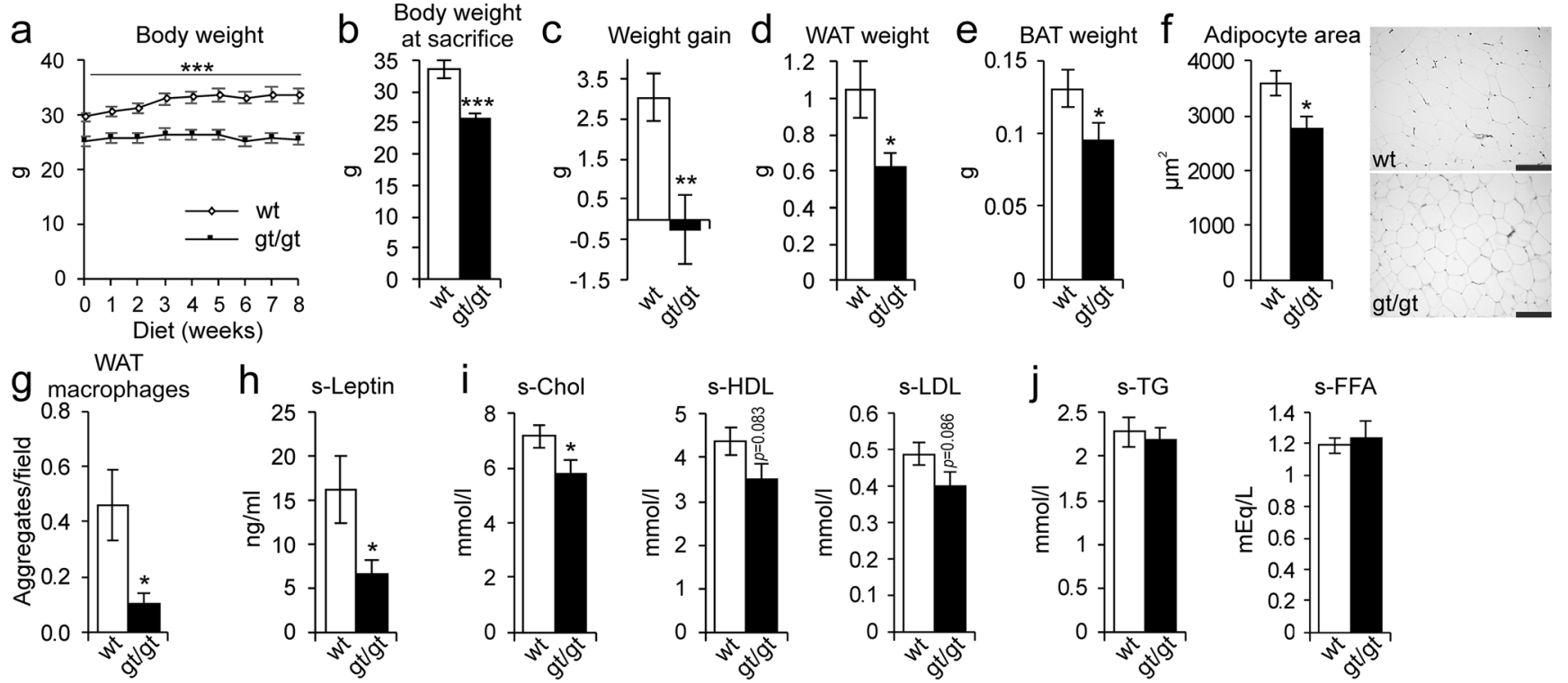

area of WAT adipocytes. Scale bar $=100 \mu \mathrm{m}$. g Number of macrophage aggregates in WAT. h Serum leptin levels. i Serum total cholesterol, HDL cholesterol, and LDL cholesterol levels. $\mathbf{j}$ Serum TG and FFA levels $(n=$ $6-10$ /group for FFA). Data are means \pm SEM. $* p<0.05$, $* * p<0.01$, $* * * p<0.001$. BAT, brown adipose tissue; FFA, free fatty acids; s, serum; $\mathrm{TG}$, triglycerides; WAT, white adipose tissue

$p 4 h-2^{\text {gt/gt }}$ livers had no steatosis, compared with $33 \%$ of the WT, while severe steatosis was observed in $>30 \%$ of the WT, but only $10 \%$ of the Hif-p $4 h-2^{\text {gt/gt }}$ livers (Fig. 2c). The HFHF diet also induced mild inflammation and fibrosis in $\sim 30 \%$ of the WT livers but not the Hif-p $4 h-2^{g^{t} / g t}$ (Fig. 2d, e). The serum ALT levels in the Hif-p $4 h-2^{g t g t}$ mice were slightly above the physiological limit (55 IU/L) whereas the WTs were at a pathological level of 107 IU/L (Fig. 2f). Similar trend was observed in the serum aspartate aminotransferase (AST) levels (Fig. 2g). Additionally, lower levels of hepatic acetyl-CoA, lipid, and cholesterol biosynthesis precursor were observed in the Hif-p4h-2 ${ }^{g t / g t}$ livers than in the WT (Fig. 2h). In agreement, many hepatic lipid metabolism mRNAs were downregulated in the Hif-p $4 h-2^{\text {gt/gt }}$ livers compared with those in WT. These included the key regulators of glucose metabolism and lipid synthesis, the glucose-activated Chrebp and the insulinactivated Srebflc, and their target genes Fasn, Scd1, and Gpam; the master regulators of hepatic lipid metabolism Ppara and Pparg along with their target genes Acsl1, Dgat1, Pnpla2, Pnpla3, Mttp, and Cd36; and the lipogenesis, fatty acid (FA) oxidation, and cholesterol metabolism mRNAs Lpin1, Lpin2, Cyp2e1, Ldlr, Hmgcr, and Hmgcs (Fig. 2i). Furthermore, the inflammation and fibrosis markers $C d 68$, F4/80, Tgfb1, Mmp 9, and Acta 2 ( $\alpha$-sma) were downregulated, corresponding to the histological findings, as was Gpxl, whose downregulation in mouse liver improves glucose metabolism and reduces steatohepatitis (Fig. 2i) [24, 25]. In agreement, a $30 \%$ decrease was observed in the protein levels
After the 8-week HFHF diet, the WT liver weights were significantly $\sim 16 \%$ higher than the Hif-p4h-2 $2^{g t / g t}$ (Fig. 2a), and consistently, the hepatic triglyceride content of the Hif-p4h$2^{\text {gt/gt }}$ livers was $>40 \%$ less than that of the WT (Fig. 2b). Histological evaluation demonstrated that $50 \%$ of the Hif- 

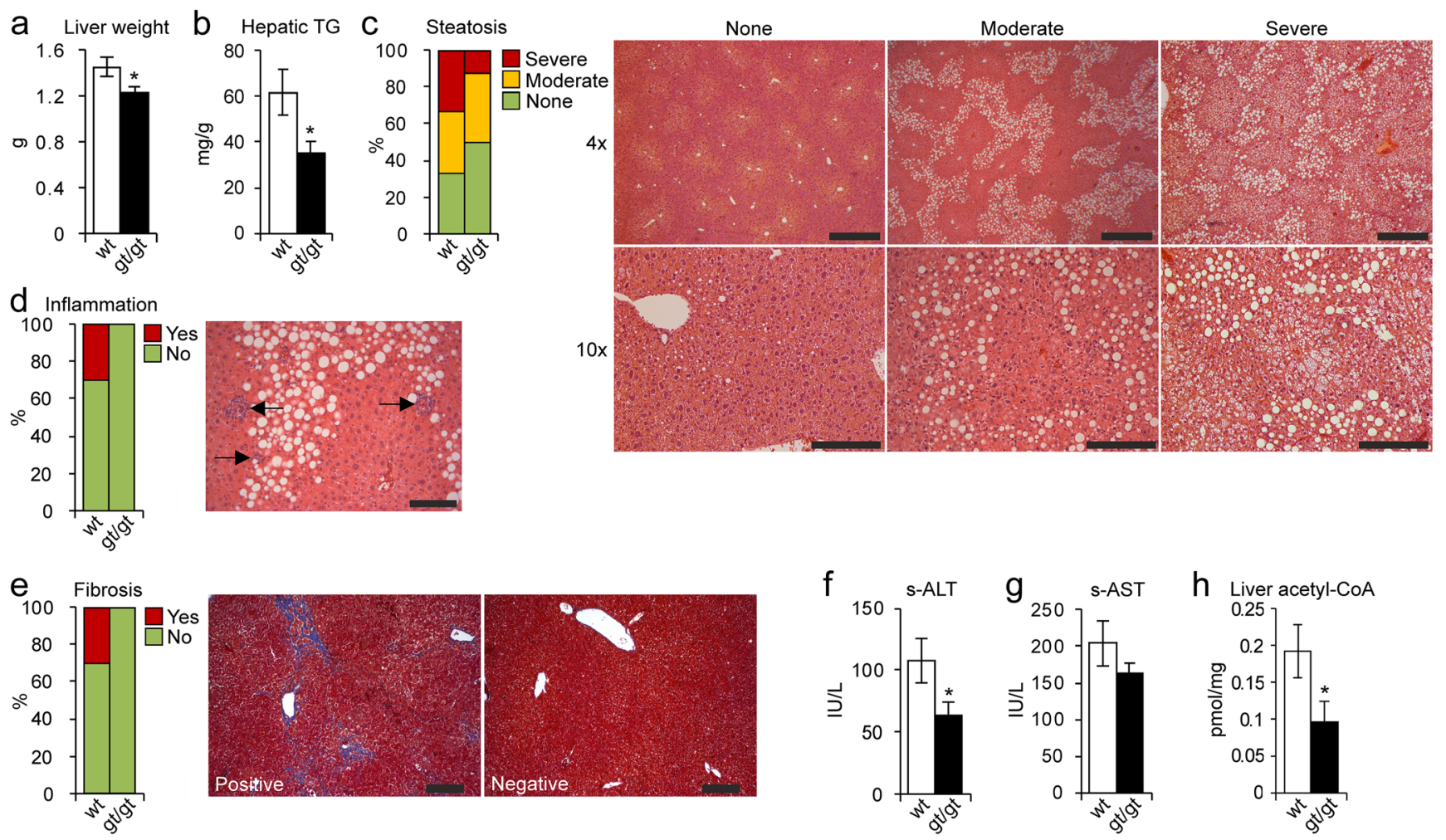

i
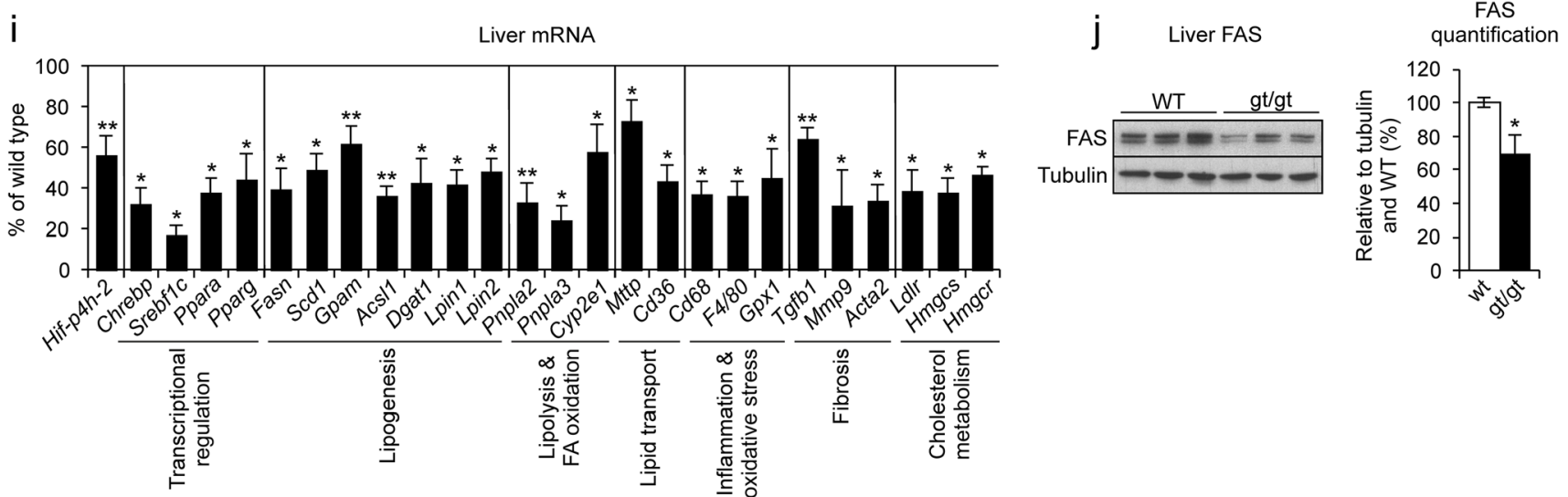

Fig. 2 HIF-P4H-2 deficiency protects mice from high-fat, high-fructose (HFHF) diet-induced fatty liver disease. Wild-type (wt) and Hif-p4h-2 ${ }^{\text {gtgt }}$ (gt/gt) males were studied while on an 8-week HFHF diet ( $n=8-10$ /group). a Liver weight. b Hepatic triglyceride content. c Scoring of steatosis and H\&E-stained liver sections. Steatosis grading: "None" corresponds to scores $0-2$, "Moderate" to 3, and "Severe" to 4. Images are representative of scoring for wt. Scale bar $=500 \mu \mathrm{m}$ for $\times 4$ and $200 \mu \mathrm{m}$ for $\times 10$. d Scoring of inflammation from H\&E-stained liver sections. "No" corresponds to score 0 and "Yes" to 1-2. Arrows indicate neutrophil clusters in wt. Scale bar $=100 \mu \mathrm{m}$. e Scoring of fibrosis from Masson's trichrome-stained liver sections. "No" corresponds to score 0 and "Yes" to 1-2. Images are representative of scoring for wt. Scale bar $=100 \mu \mathrm{m}$. f Serum ALT levels. g Serum AST levels. h Liver acetyl-CoA levels. i qPCR analysis of liver mRNA levels of gt/gt mice relative to wt, studied relative to TATA-box-binding protein mRNA. j Western blotting and densitometric quantification of hepatic FAS levels ( $n=4 /$ group.). Tubulin

of FAS in the Hif-p4h-2 ${ }^{\text {gt/gt }}$ livers (Fig. 2j). The hepatic Hifp4h-2 mRNA levels were down to a similar extent ( $40 \%)$ as reported earlier [14] (Fig. 2i), and the protein levels of HIF- was used as a loading control. a, b, f-j Data are means \pm SEM. $* p \leq 0.05$, $*^{*} p<0.01$. ACSL1, acyl-CoA synthetase long-chain family member 1 ; ACTA2, actin alpha 2, smooth muscle; ALT, alanine aminotransferase; AST, aspartate aminotransferase; CHREBP, carbohydrate-responsive element-binding protein; CYP2E1, cytochrome P450 family-2 subfamily e member 1; DGAT1, diacylglycerol o-acyltransferase 1; FAS/FASN, fatty acid synthase; FA, fatty acid; GPAM, mitochondrial glycerol-3-phosphate acyltransferase; GPX1, glutathione peroxidase 1; HMGCS/HMGCR, hydroxymethylglutaryl-CoA synthase/reductase; LDLR, low-density lipoprotein receptor; LPIN, lipin; MMP9, matrix metallopeptidase 9; MTTP, microsomal triglyceride transfer protein; PNPLA, patatin-like phospholipase domain containing; PPAR a/g, peroxisome proliferatoractivated receptor alpha/gamma; s, serum; SCD1, stearoyl-CoA desaturase 1; SREBF1c, sterol regulatory element-binding protein 1c; TG, triglycerides; TGFb1, transforming growth factor beta 1

P4H-2, studied with baseline Hif-p4h-2 $2^{g t / g t}$ and WT primary hepatocytes, were correspondingly downregulated (Fig. S2). Altogether, these data indicate that the Hif-p4h-2 $2^{g t g t}$ mice 

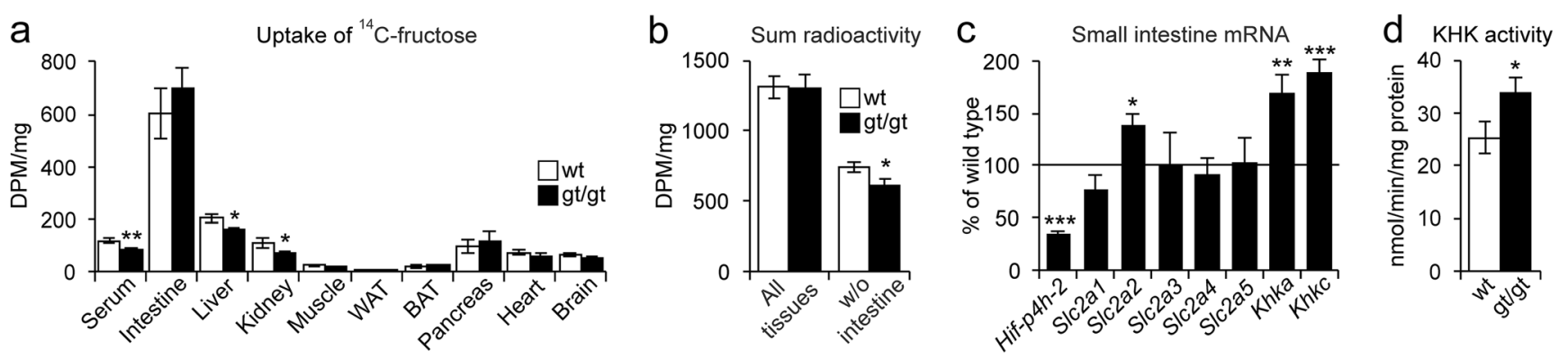
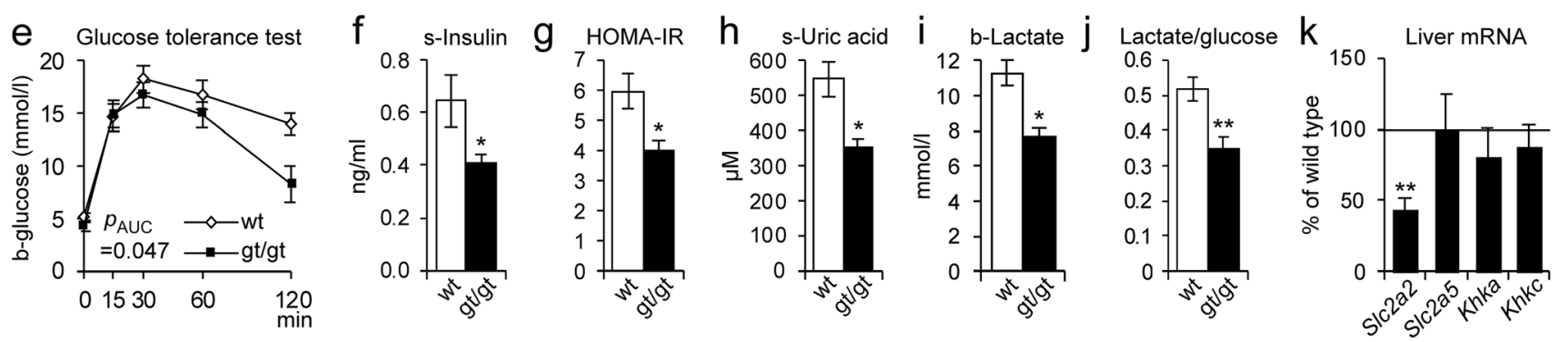

Fig. 3 Changes in fructose metabolism associated with protection from high-fat, high-fructose (HFHF) diet-induced NAFLD in the HIF-P4H-2deficient mice. Wild-type (wt) and Hif-p4h- $2^{\mathrm{gt} / \mathrm{gt}}(\mathrm{gt} / \mathrm{gt})$ males after e-g 6 or $\mathbf{c}, \mathbf{h}-\mathbf{k} 8$ weeks on a HFHF diet ( $n=8-10$ /group). a, b ${ }^{14} \mathrm{C}$-fructose uptake test. After 2 weeks on the HFHF diet and a 12-h fast, wt and gt/gt females received ${ }^{14} \mathrm{C}$-fructose orally and were sacrificed after $15 \mathrm{~min}$ and tissue samples were measured for ${ }^{14} \mathrm{C}$ radioactivity as disintegration $/ \mathrm{min} / \mathrm{mg}$ (DPM) ( $n=12$ /group). a DPM per mg of tissue in indicated tissues. b Sum radioactivity detected in all tissues measured including and excluding the small intestine. $\mathbf{c}$ qPCR analysis of the mRNA levels of glucose and fructose transporters and metabolizing enzymes in the small intestine of the gt/gt mice relative to wt. Gene expression was studied relative to $\beta$-actin mRNA. d Ketohexokinase activity in the small intestine of females after

were protected from HFHF diet-induced metabolic symptoms of NAFLD, hepatic fat accumulation, and liver damage.

\section{HIF-P4H-2-deficient mice had lower hepatic fructose levels and better glucose tolerance on the HFHF diet than the WT}

We next studied the ${ }^{14} \mathrm{C}$-labeled fructose uptake by tissues $15 \mathrm{~min}$ after oral administration. Majority of radioactivity was found in the intestine in both genotypes (Fig. 3a) while no difference was seen in its secretion to feces or urine between the genotypes (Fig. S3a). Interestingly, the ${ }^{14} \mathrm{C}$ levels measured in most tissues were 15-35\% lower in the Hif-p4h-2 ${ }^{\text {gt/gt }}$ mice than in the WT, the reduction in the liver, kidney, and serum reaching significance, unlike the induction of $\sim 20 \%$ in the intestine, pancreas, and BAT (Fig. 3a). The sum of radioactivity in all tissues was similar in both genotypes (Fig. 3b), but the sum excluding the intestine was significantly lower in the Hif-p $4 h$ $2^{g t g t}$ mice, suggesting that the lower amount of fructose found in the liver, kidney, and serum would correspond to increased uptake by the Hif-p $4 h-2^{g t / g t}$ intestine (Fig. 3a). The small intestine metabolizes most of dietary fructose ketohexokinase (KHK) dependently, and if its clearance capacity is exceeded
4 weeks on a HFHF diet ( $n=6-8 /$ group). e Oral glucose tolerance test (GTT). The value for 0 min was determined after a $12-\mathrm{h}$ fast. f Serum insulin levels determined from the 0-min GTT samples. g HOMA-IR scores determined from the 0 -min values. h Serum uric acid levels. i Blood lactate levels. $\mathbf{j}$ Blood lactate-to-glucose ratio. $\mathbf{k}$ qPCR analysis of liver mRNA levels of glucose and fructose transporters and metabolizing enzymes in $\mathrm{gt} / \mathrm{gt}$ mice relative to wt, studied relative to TATA-box-binding protein mRNA. Data are means \pm SEM. $* p<0.05, * * p<0.01$, $* * * p<0.001$. The $p$ value for $\mathbf{d}$ was calculated from $\log$-transformed values. b, blood; BAT, brown adipose tissue; HOMA-IR, homeostatic model assessment-insulin resistance; KHK, ketohexokinase; s, serum; SLC2A 1-5, solute carrier family-2 member 1-5; WAT, white adipose tissue

by high fructose concentration, the excess fructose spills over into the liver and other organs, as reported previously [26]. Therefore, we studied the mRNA levels of KHK isoenzymes and fructose transporters and found upregulation of Slc2a2 (GLUT2) mRNA levels in the Hif-p $4 h-2^{\text {gtgt }}$ small intestine relative to the WT, the downregulation of Hif-p $4 h-2$ mRNA being $\sim 65 \%$ in the intestine in the former (Fig. 3c). However, no difference was seen in the immunostaining of GLUT2 (Fig. $\mathrm{S} 3 \mathrm{~b})$. Interestingly, the $K h k a$ and $K h k c$ mRNA levels were significantly higher in the Hif-p4h-2 $2^{\text {gtgt }}$ small intestine than in the WT (Fig. 3c) as was the measured catalytic KHK activity (Fig. 3d). Altogether, these data suggest enhanced fructose metabolism in the Hif-p $4 h-2^{g t / g t}$ intestine, which would result in less fructose being transported to the liver and other tissues.

Furthermore, the HFHF-fed Hif-p $4 h-2^{g t g t}$ mice maintained a better glucose tolerance than the WT and had lower serum insulin levels and HOMA-IR scores, indicating better insulin sensitivity (Fig. 3e-g). A similar reduction was seen in circulating levels of the harmful byproducts of fructose metabolism, uric acid, and lactate (Fig. 3h, i), supporting differences in its metabolism between genotypes. This, and the lower lactate/glucose ratio in the Hif-p $4 h-2^{\text {gttgt }}$ mice (Fig. 3j), agrees with their previously characterized enhanced lactate clearance [27]. The hepatic 
mRNA level of the fructose-uptaking Slc2a2 was significantly lower in the Hif-p4h-2 ${ }^{\text {gtgt }}$ than in the WT, supporting the reduced hepatic ${ }^{14} \mathrm{C}$-fructose uptake, while there was no difference between the genotypes in the levels of Slc2a 5 or Khks (Fig. 3k). Of note, the expression level of Slc2a2 mRNA was $\sim 65$-fold compared Slc2a5 (data not shown), being in agreement with the role of GLUT2 as the main hepatic fructose transporter.

\section{HIF-P4H-2-deficient mice were protected from obesity and retained a healthier serum lipid profile when challenged with an HF-MCD diet}

Next, the Hif-p $4 h-2^{g t / g t}$ and WT mice were fed the HF-MCD diet, inducing a more severe form of NAFLD than the HFHF diet. The weight gain of the Hif-p $4 h-2^{\text {gt/gt }}$ mice was significantly lower than that of the WT during the 7-week diet, and at sacrifice, they had a $22 \%$ lower body weight (Fig. $4 \mathrm{a}-\mathrm{c}$ ). In agreement, the Hif-p $4 h-2^{g t / g t}$ mice had $45 \%$ less WAT than the WT with significantly smaller adipocytes and a trend towards lower BAT weight (Fig. 4d-f). Also, less macrophage aggregates were detected in their WAT (Fig. 4g). Additionally, the Hif-p $4 h-2^{g t / g t}$ mice retained a healthier serum lipid profile than the WT, their total cholesterol level being significantly lower (Fig. $4 \mathrm{~h}$ ), the same applying to their glucose levels (Fig. S4). No differences in serum triglyceride and FFA levels were detected between the genotypes on this diet, either (Fig. 1i).

\section{Hif-p $4 h-2^{g t / g t}$ mice were protected against HF-MCD diet-induced steatosis and liver damage}

The liver weights of the Hif-p $4 h-2^{g t / g t}$ mice were $>20 \%$ lower than those of the WT after the HF-MCD diet (Fig. 5a). Consistently, the Hif-p $4 h-2^{g t / g t}$ livers had a significantly lower hepatic triglyceride content (Fig. 5b) and histological scores for steatosis severity, $\sim 35 \%$ of the Hif-p $4 h-2^{\text {tt/gt }}$ livers against $\sim 70 \%$ of WT scored as "very severe" (Fig. 5 c). Only mild inflammation (Fig. 5d) and fibrosis (Fig. S5a) were detected to similar extents in both genotypes. Serum ALT and AST were elevated to a pathological level in both genotypes, but they were significantly $~ 30 \%$ lower in the Hif-p $4 h-2^{\text {gttgt }}$ than in the WT mice (Fig. 5e, f). Additionally, the serum albumin levels were significantly higher for the Hif-p4h-2 $2^{g t g t}$ mice than for the WT (Fig. 5g), and the Hif-p4h-2 ${ }^{\text {gt/gt }}$ livers had more proliferating cells than the WT (Fig. 5h) with no difference in apoptosis (Fig. S5b), suggesting enhanced regeneration in the Hif-p $4 h-2^{\text {ttgt }}$ livers. Both genotypes' livers showed similar dispersed expression of pericentral zonation marker glutamine synthetase (Fig. S5c). In agreement with less fat accumulation and damage detected in the Hif-p $4 h-2^{g t / g t}$ livers than in the WT, the hepatic expression levels of several lipid metabolism and oxidative stress mRNAs were lower, while the Hif-p4h-2 mRNA downregulation was similar to that on the HFHF diet (Figs. 5i and S5d). Additionally, the levels of all cholesterol synthesis precursors but squalene were reduced in the Hif-p $4 h-2^{\text {tt/gt }}$ liver compared with that in the
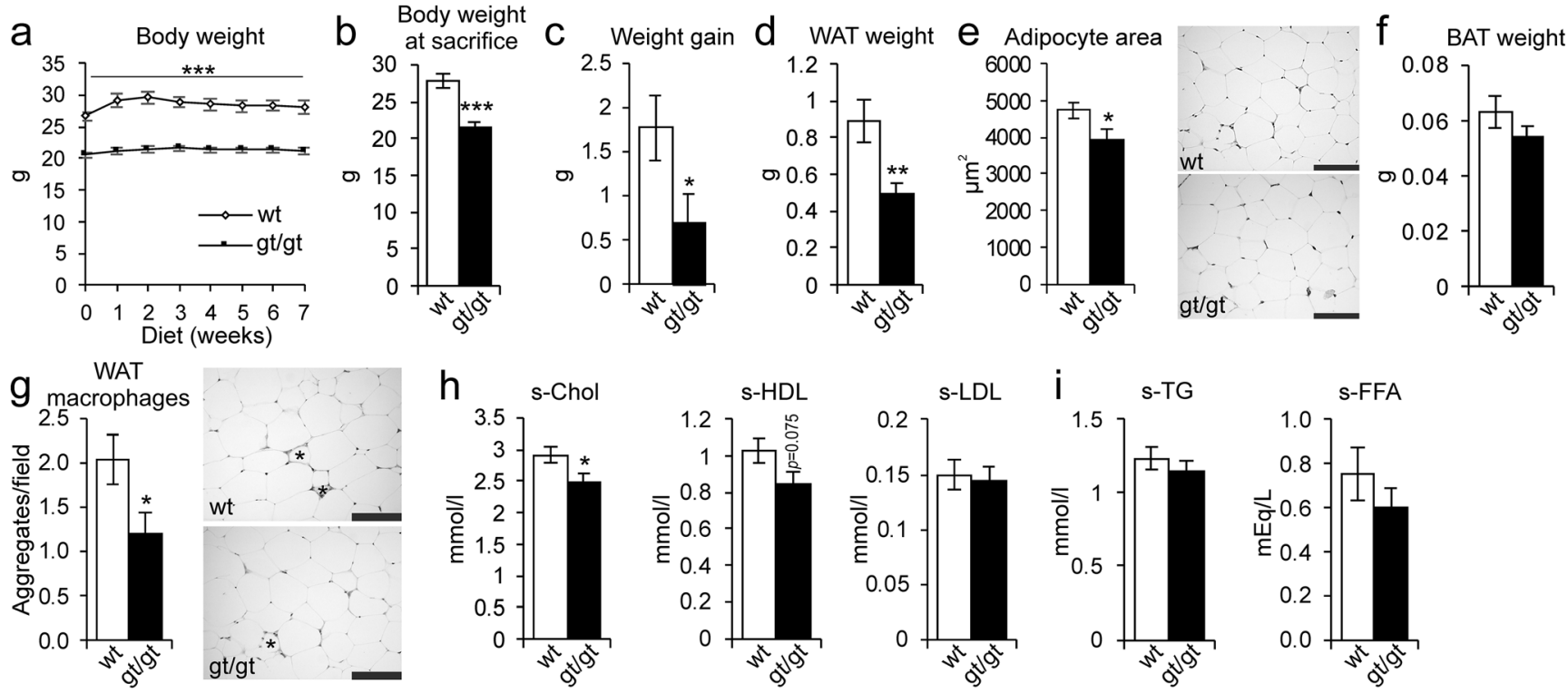

Fig. 4 HIF-P4H-2-deficient mice are protected against HF-MCD dietinduced obesity, adipose tissue inflammation, and higher cholesterol levels. Wild-type (wt) and Hif-p4h-2 ${ }^{\mathrm{gt} / \mathrm{gt}}$ (gt/gt) females were studied while on a 7-week high-fat, methionine-choline-deficient (HF-MCD) diet ( $n=10-12$ /group). a Body weight development during the 7 weeks. b Body weight at sacrifice. $\mathbf{c}$ Weight gain at the end of the diet relative to weights on the day before the diet started. d Weight of gonadal WAT. e
Cross-sectional area of WAT adipocytes. Scale bar $=100 \mu \mathrm{m}$. f Weight of BAT. g Number of macrophage aggregates in WAT. *Adipocytes surrounded by macrophage aggregates. Scale bar $=100 \mu \mathrm{m}$. h Serum total cholesterol, HDL cholesterol, and LDL cholesterol levels. i Serum TG and FFA levels ( $n=6-9 /$ group). Data are means \pm SEM. ${ }^{*} p<0.05$, $* * p<0.01, * * * p<0.001$. BAT, brown adipose tissue; FFA, free fatty acids; s, serum; TG, triglycerides; WAT, white adipose tissue 

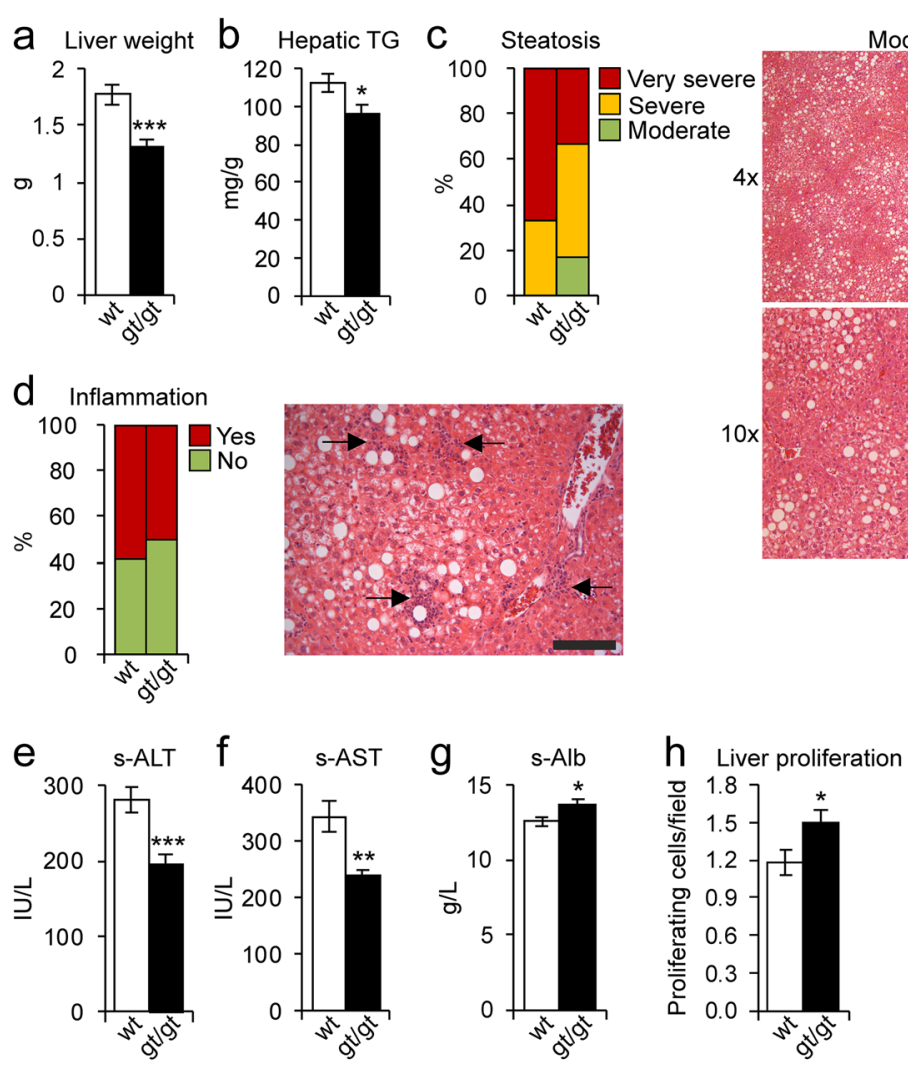

Fig. 5 HIF-P4H-2 deficiency protects mice from HF-MCD diet-induced fatty liver disease. Wild-type (wt) and Hif-p4h-2 ${ }^{\text {gt/gt }}$ (gt/gt) females were studied while on a 7-week high-fat, methionine-choline-deficient (HFMCD) diet ( $n=10-12$ group). a Liver weight. b Hepatic triglyceride content. c Scoring of steatosis and H\&E-stained liver sections. Steatosis grading: "Moderate" corresponds to score 2, "Severe" to 3, and "Very severe" to 4. "Very severe" and "severe" images are representative of scoring for wt, and "moderate" for gt/gt. Scale bar $=500 \mu \mathrm{m}$ for $\times 4$ and $200 \mu \mathrm{m}$ for $\times 10$. d Scoring of inflammation from H\&E-stained liver sections. "No" corresponds to scores $0-1$ and "Yes" to 2-4. Arrows indicate neutrophil clusters in wt. Scale bar $=100 \mu \mathrm{m}$. e Serum ALT

WT (Table S2), which suggests downregulated cholesterol synthesis in the former, likely contributing to the observed lower serum cholesterol levels (Fig. 4h). Additionally, serum uric acid levels were significantly lower in the Hif-p $4 h$ $2^{g t / g t}$ mice, while no differences were detected in the FGF21 levels (Fig. S5e, f). These data indicate that the Hif-p $4 h-2^{g t /}$ ${ }^{g t}$ mice showed protection against the HF-MCD dietinduced hepatic fat accumulation and damage compared with the WT.

\section{Increased heat production in the HIF-P4H-2-deficient mice on an HF-MCD diet is associated with protection from NAFLD}

Browning of WAT has been shown to be a protective mechanism against NAFLD in mice on MCD diet [28, 29]. Therefore, we next studied the expression of
Moderate
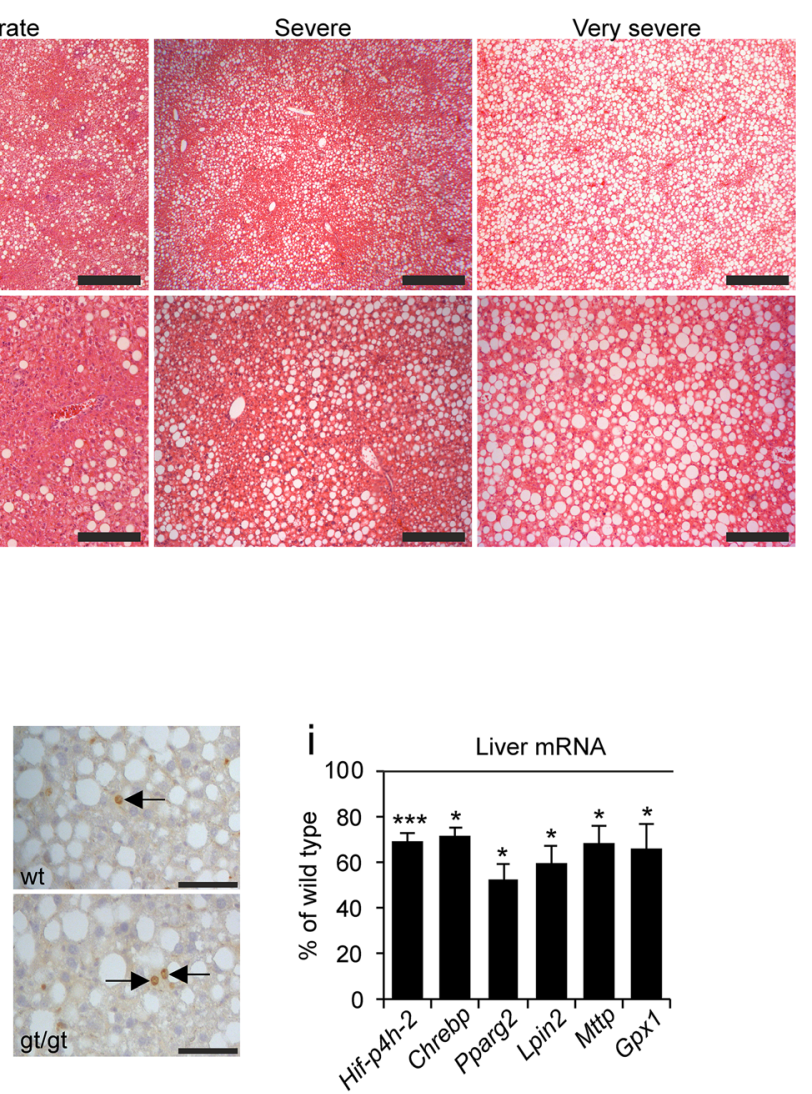

levels. f Serum AST levels. g Serum albumin levels ( $n=9-10 /$ group). $\mathbf{h}$ Number of Ki67-positive proliferating cells in the liver sections. Arrows indicate Ki67-positive cells. Scale bar $=50 \mu \mathrm{m}$. i qPCR analysis of liver mRNA levels of gt/gt mice relative to wt, studied relative to TATA-boxbinding protein mRNA. a, b, e-i Data are means \pm SEM. ${ }^{*} p<0.05$, $* * p<0.01, * * * p<0.001$. Alb, albumin; ALT, alanine aminotransferase; AST, aspartate aminotransferase; CHREBP, carbohydrate-responsive element-binding protein; GPX1, glutathione peroxidase 1; LPIN, lipin; MTTP, microsomal triglyceride transfer protein; PPARg2, peroxisome proliferator-activated receptor gamma 2; s, serum; TG, triglycerides

uncoupling protein 1 (UCP1) in the WAT of the HFMCD diet-fed mice. Surprisingly, the Hif-p $4 h-2^{\text {gt } / g t}$ mice showed significantly more UCP1 expression $(83.3 \%)$ than the WT (33.3\%) (Fig. 6a), verified by Western blotting (Fig. 6b). No difference between the genotypes in BAT UCP1 levels was detected (data not shown). In agreement, the mRNA levels of the browning markers Ucp1, Ppara, Pparg, Pparg2, Cebpa, Prdm16, Vegfa, Ppargcla, Acsl1, and Lipe were significantly upregulated in the Hif-p $4 h-2^{g t}$ ${ }^{g t}$ WAT relative to the WT, the downregulation of Hif-p $4 h$ 2 mRNA being similar to that on normal chow [14] (Fig. 6c). Since UCP1 expression relates to heat production, we submitted the mice on the HF-MCD diet for indirect gas calorimetry analysis, which showed significantly increased heat production by the Hif-p $4 h-2^{g t / g t}$ mice compared with the WT (Fig. 6d). There was no difference between the genotypes in physical activity, 


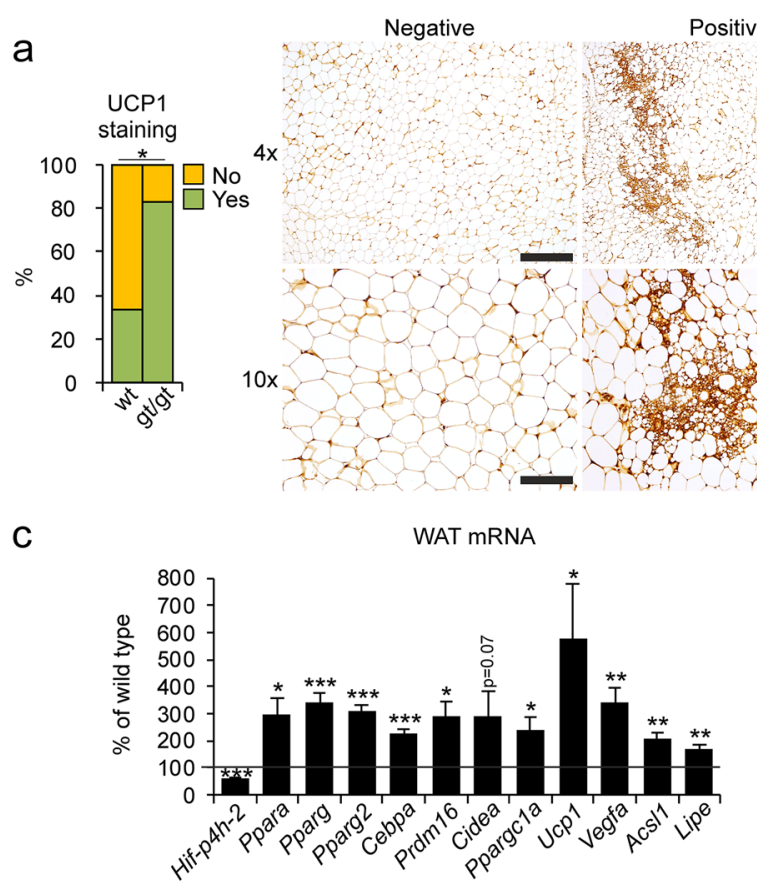

e

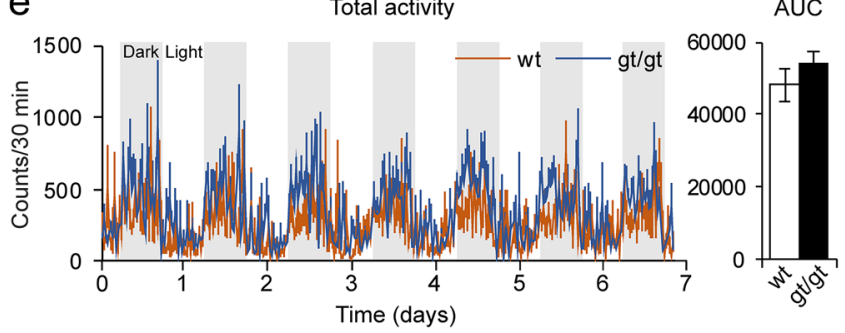

g

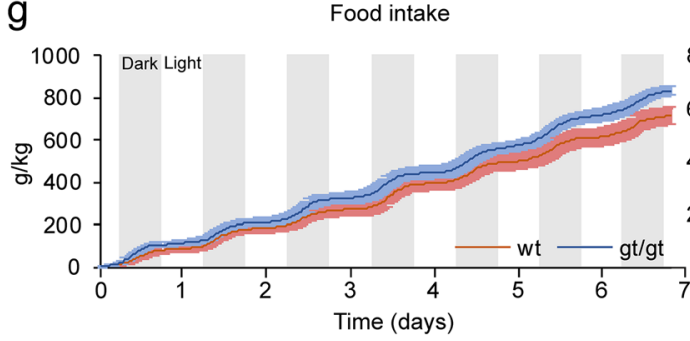

AUC

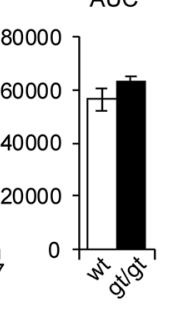

Fig. 6 Heat production via UCP1 activation in the WAT is associated with protection from HF-MCD diet-induced NAFLD in HIF-P4H-2deficient mice. Wild-type (wt) and Hif-p4h-2 ${ }^{\mathrm{gt} / \mathrm{gt}}$ (gt/gt) females were studied while on a 7-week high-fat, methionine-choline-deficient (HFMCD) diet. a Scoring of UCP1-stained WAT sections. "No" corresponds to $<5 \%$ of UCP1 staining/field and "Yes" to $5-25 \%$ ( $n=10-12 /$ group). Images are representative of scoring for wt. Scale bar $=500 \mu \mathrm{m}$ for $\times 4$ and $200 \mu \mathrm{m}$ for $\times 10$. b Western blotting and densitometric quantification of WAT UCP1 levels ( $n=3-4$ /group.). $\beta$-Actin was used as a loading control. $\mathbf{c}$ qPCR analysis of the mRNA levels of browning markers in the WAT of the $\mathrm{gt} / \mathrm{gt}$ mice relative to wt ( $n=10-12 /$ group). Gene expression was studied relative to $\beta$-actin mRNA. $\mathbf{d}-\mathbf{h}$ Mice were analyzed in

respiratory exchange ratio, or food intake (Fig. 6e-g), but an increase in water intake was observed in the Hif-p4h$2^{g t / g t}$ mice (Fig. 6h). These differences were not observed in previous measurements on normal chow [14], neither in the baseline measurements preceding the HF-MCD diet

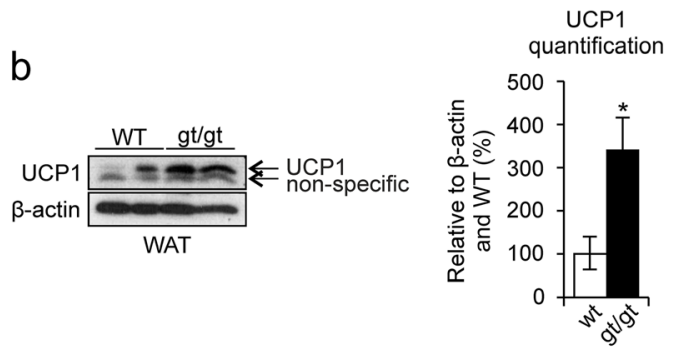

d
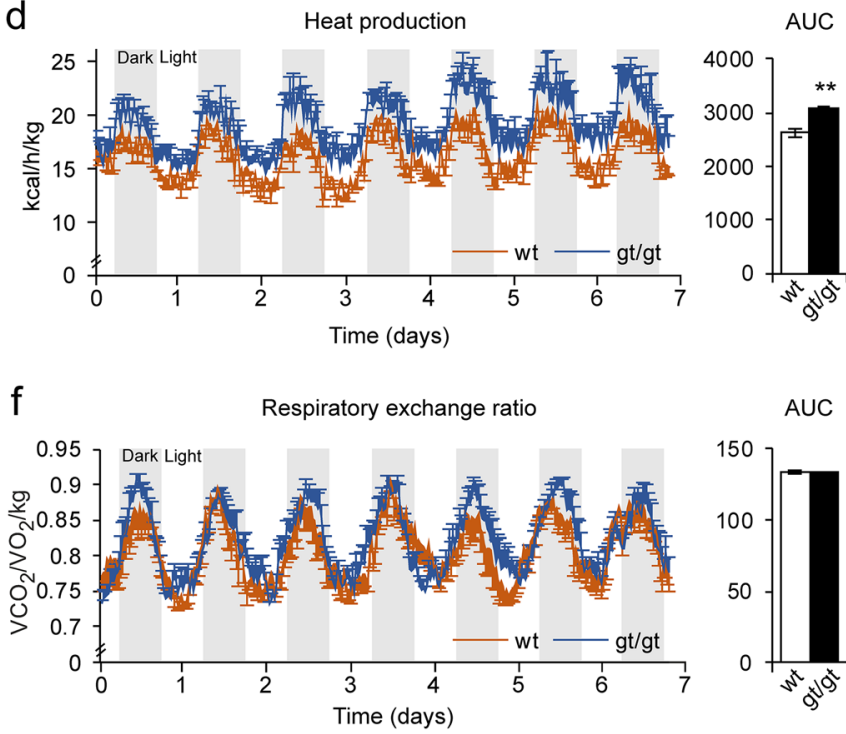

h
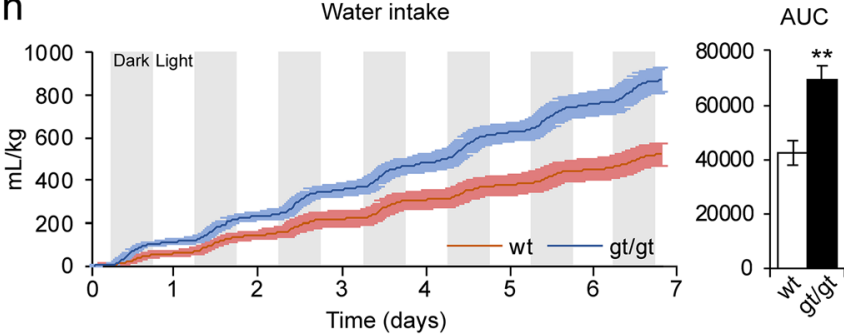

metabolic home cages for the last week of the diet ( $n=7-8 /$ group). d Heat production and AUC. e Total physical activity and AUC. f Respiratory exchange ratio $\left(\mathrm{VCO}_{2} / \mathrm{VO}_{2} / \mathrm{kg}\right)$ and AUC. g Food intake and AUC. $\mathbf{h}$ Water intake and AUC. $\mathbf{b}-\mathbf{h}$ Data are means \pm SEM. $* p<0.05, * * p<0.01, * * * p<0.001$. ACSL1, acyl-CoA synthetase long-chain family member 1 ; AUC, area under the curve; CEBPA, CCAAT-enhancer-binding protein alpha; CIDEA, cell death-inducing DFFA-like effector A; LIPE, hormone-sensitive lipase; PPAR a/g, peroxisome proliferator-activated receptor alpha/gamma; PPARGC1A, PPARg coactivator-1 alpha; PRDM16, PR/SET domain-16; UCP1, uncoupling protein 1; VEGFA, vascular endothelial growth factor A; WAT, white adipose tissue

feeding, and no browning was detected in either genotype on the HFHF diet (data not shown). These data suggest that the Hif-p $4 h-2^{g t / g t}$ mice used advanced browning of WAT as a mechanism of protection against HF-MCD diet-induced NAFLD. 

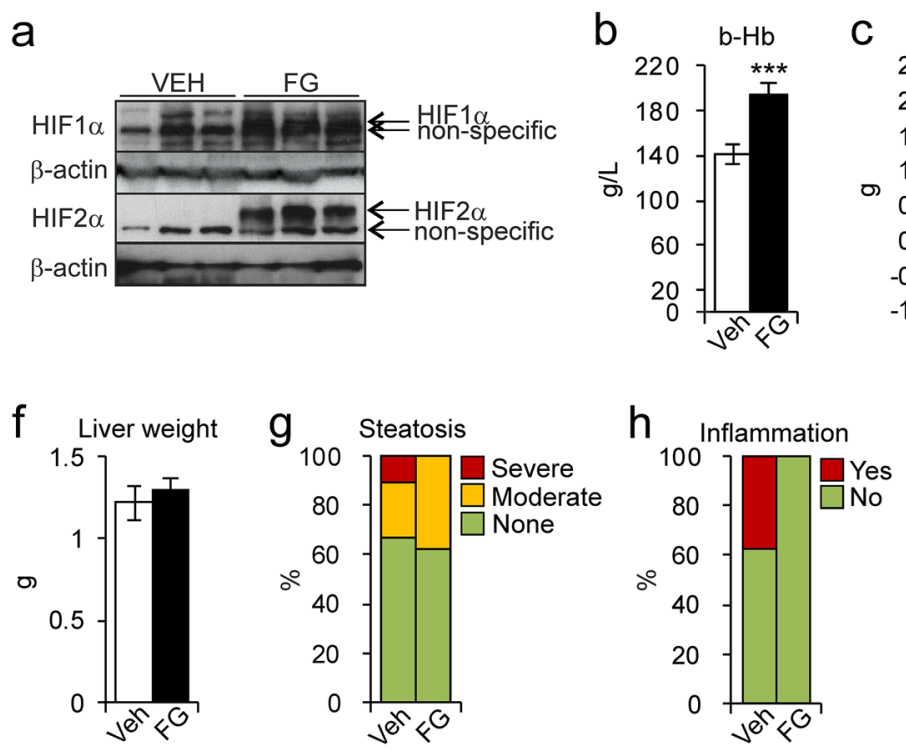
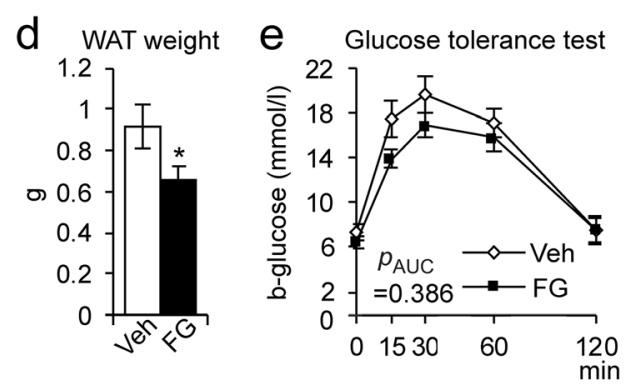
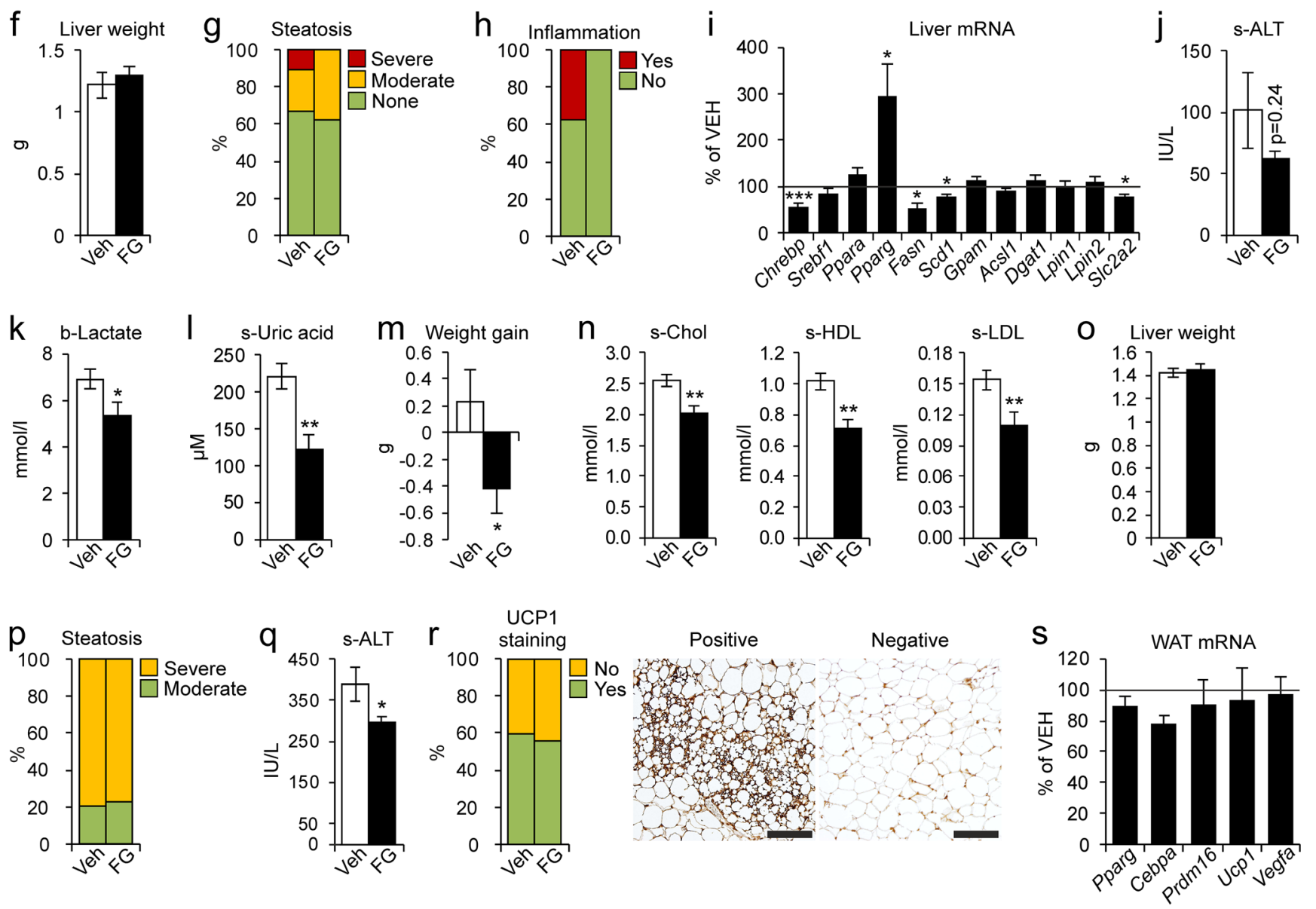

Fig. 7 Pharmacological inhibition of HIF-P4Hs ameliorates diet-induced obesity, metabolic dysfunction, and liver damage. Wild-type (wt) females were fed a high-fat, high-fructose (HFHF) diet for e 4 or a-d, $\mathbf{f}-\mathbf{l} 6$ weeks or a high-fat, methionine-choline-deficient (HF-MCD) diet for $\mathbf{m}-\mathbf{s}$ 3 weeks and simultaneously given vehicle (VEH) or $60 \mathrm{mg} / \mathrm{kg}$ of FG4497 (FG) on days 1,3 , and 5 of each week ( $n=8-10$ /group). a Western blot analysis of hepatic HIF $1 \alpha$ and HIF $2 \alpha$ protein levels. $\beta$-Actin was used as a loading control. b Blood hemoglobin levels. $\mathbf{c}$ Weight gain at the end of the diet relative to weights on the day before the diet started. d Weight of gonadal WAT. e Oral glucose tolerance test. The value for 0 min was determined after a 12 -h fast. f Liver weight. g Scoring of hepatic steatosis. Steatosis grading: "None" corresponds to scores 0-2, "Moderate" to 3, and "Severe" to 4. h Scoring of liver inflammation. "No" corresponds to score 0 and "Yes" to 1-2. i qPCR analysis of liver mRNA levels of FG-treated mice relative to VEH-treated, studied relative to TATA-box-binding protein mRNA. j Serum ALT levels. k Blood lactate levels. I Serum uric acid levels. $\mathbf{m}$ Weight gain at the end of the HFMCD diet relative to weights on the day before the diet started. $\mathbf{n}$ Serum total cholesterol, HDL cholesterol, and LDL cholesterol levels. o Liver weight. p Scoring of hepatic steatosis. Steatosis grading: "Moderate" corresponds to score 2 and "Severe" to 3. q Serum ALT levels. $\mathbf{r}$ Scoring of UCP1-stained WAT sections. "No" corresponds to $<5 \%$ of UCP1 staining/field and "Yes" to 5-25\%. Images are representative of scoring for the VEH group. Scale bar $=200 \mu \mathrm{m}$. s qPCR analysis of WAT mRNA levels of FG-treated mice relative to VEH-treated group, studied relative to peptidylprolyl isomerase A mRNA. b-f, $\mathbf{i}-\mathbf{o}, \mathbf{q}, \mathbf{s}$ Data are means \pm SEM. $* p \leq 0.05, * * p<0.01, * * * p<0.001$. ACSL1, acyl-CoA synthetase long-chain family member 1; ALT, alanine aminotransferase; b, blood; CEBPA, CCAAT-enhancer-binding protein alpha; CHREBP, carbohydrate-responsive element-binding protein; DGAT1, diacylglycerol o-acyltransferase 1; FASN, fatty acid synthase; GPAM, mitochondrial glycerol-3-phosphate acyltransferase; LPIN, lipin; PPAR a/g, peroxisome proliferator-activated receptor alpha/gamma; PRDM16, PR/SET domain-16; s, serum; SCD1, stearoyl-CoA desaturase 1; SLC2A2, solute carrier family-2 member 2; SREBF1c, sterol regulatory element-binding protein 1c; UCP-1, uncoupling protein 1; VEGFA, vascular endothelial growth factor A; WAT, white adipose tissue 


\section{Pharmacological inhibition of HIF-P4Hs ameliorates diet-induced obesity, metabolic dysfunction, and NAFLD}

WT mice were fed the HFHF diet for 6 weeks and simultaneously treated with a pharmacological pan-HIF-P4H inhibitor FG-4497 or vehicle. The FG-4497 treatment stabilized HIF $1 \alpha$ and HIF $2 \alpha$ in the livers (Fig. 7a) and elevated the blood hemoglobin levels (Fig. 7b). The FG-4497-treated mice did not gain weight (Fig. 7c) and had less WAT (Fig. 7d) than the vehicle-treated mice. They also showed a trend towards a better glucose tolerance (Fig. 7e). However, no significant differences in liver weight or steatosis were detected between groups (Fig. 7f, g), liver inflammation being detected only in the vehicle-treated group (Fig. 7h). The inability of the FG4497 treatment to protect against steatosis compared with the Hif-p $4 h-2^{g t / g t}$ livers associated with only a few lipogenic mRNAs and Slc2a2 being downregulated, and conversely with Pparg mRNA upregulation (Fig. 7i). Although not significant, the serum ALT levels were $\sim 40 \%$ lower in the FG4497 group (Fig. 7j), indicating less liver damage, possibly stemming from lower intake of fructose due to Slc2a2 downregulation. Moreover, systemic levels of lactate and uric acid were significantly lower in the FG-4497-treated group (Fig. 7k, 1). In conclusion, the FG-4497 treatment stabilized HIF, protecting from the HFHF diet-induced obesity and hepatic inflammation, but not from steatosis.

We next fed WT mice the HF-MCD diet for 3 weeks with simultaneous FG-4497 or vehicle treatment. The FG-4497 treatment was protected from weight gain (Fig. $7 \mathrm{~m}$ ) and the mice had a healthier serum lipid profile than the vehicletreated group (Fig. 7n), but no difference in liver weight or steatosis was detected between the groups (Fig. 7o, p). Nevertheless, the FG-4497-treated mice had lower serum ALT levels (Fig. 7q). Lastly, similar expression levels of WAT UCP1 and browning marker mRNAs were detected in both groups (Fig. 7r, s). In conclusion, the FG-4497 treatment on the HF-MCD diet was protected from obesity, hypercholesterolemia, and liver damage, but could not induce browning of WAT to the extent seen in the Hif-p $4 h-2^{g t / g t}$ mice and thus, was unable to protect against steatosis.

\section{Discussion}

Obesity and WAT function play key roles in the progression of NAFLD, since obesity and IR induce adipose tissue lipolysis and the liver then accumulates circulating FAs in a concentration-dependent manner [30]. Fructose contributes to NAFLD by providing a substrate for increased FA synthesis and activating hepatic de novo lipogenesis, which it promotes directly by upregulating SREBP1c [31], and indirectly by uric acid production, which reduces mitochondrial $\beta$-oxidation resulting in oxidative stress, hepatic IR, and endoplasmic reticulum (ER) stress [32, 33]. Absorbed fructose is transported via the portal vein, thus reaching the liver in higher concentrations than the other tissues.

The roles of HIFs and HIF-P4Hs in NAFLD are complex and not yet fully understood. The data available until this study is mainly from liver/hepatocyte-specific settings and suggest that stabilization of HIF $2 \alpha$, or simultaneous inhibition of all HIF-P4Hs, promotes NAFLD while restricting the inhibition to selected isoenzymes may have beneficial effects [14, 34-38]. We have reported earlier that normal chow-fed Hif$p 4 h-2^{\text {gt/gt }}$ mice have hepatic stabilization of HIF $2 \alpha$ but not of HIF $1 \alpha$ with upregulation of Irs 2 and downregulation of Srebflc mRNA, resulting in lower acetyl-CoA levels, reduced de novo lipogenesis, and lower IR than the WT [14, 17]. Furthermore, we recently showed that mouse embryonic fibroblasts isolated from Hif-p $4 h-2^{g t / g t}$ mice show $\sim 50 \%$ reduced ATP production compared with WT cells, likely resulting in the baseline differences in adiposity $[14,18]$. We now show that Hif-p $4 h-2^{g t / g t}$ mice were able to resist weight gain and adiposity on a HFHF diet and had less hepatic steatosis and liver damage and no inflammation or fibrosis. These features associated with downregulation of lipogenic mRNAs, lower levels of hepatic acetyl-CoA and serum insulin, and better glucose tolerance. Moreover, differences in fructose metabolism in favor of the Hif-p $4 h-2^{g t / g t}$ mice were detected, including 20-33\% less fructose found in the liver, kidney, and serum than in the WT, and lower levels of serum uric acid and lactate. Interestingly, the mRNA levels and enzymatic activity of KHKs, which are responsible for the cleavage of fructose, were upregulated in the small intestine of the Hif-p $4 h-2^{g t / g t}$ mice. The small intestine is the major site of fructose metabolism when ingested in low doses, whereas fructose spills over into the liver at high doses [26]. Our data suggest that inhibition of HIF-P4H-2 increases the capacity of the intestine to metabolize high doses of dietary fructose and therefore provides protection from its spillover into the liver and other tissues.

Moreover, the Hif-p $4 h-2^{g t / g t}$ mice on a HFHF diet expressed hepatic mRNAs for Pnpla2, Pnpla3, and Cyp2e1 at lower levels than the WT. Inhibition of the adipose ligase PNPLA2 has been associated with protection against ER stress in mice [39, 40], while activating genetic variants in PNPLA3 are associated with human NAFLD [41]. Moreover, increased expression of hepatic CYP2E1, which carries out the omega-hydroxylation of FAs, has been associated with NASH in mice and humans [42].

Additionally, the Hif-p4h-2 ${ }^{g t / g t}$ mice on the HF-MCD diet had less WAT, and interestingly, they showed improved browning of WAT, which was associated with increased heat production. This likely contributed to less hepatic steatosis in the Hif-p $4 h-2^{g t / g t}$ mice, as WAT browning protecting against 
NAFLD has been reported on an MCD diet [28, 29]. However, this is the first report associating HIF-P4H inhibition with induced browning of WAT and increased thermogenesis, while earlier reports associate environmental hypoxia with HIF pathway activation and WAT browning [43, 44]. This likely involves the observed upregulation of adipose tissue PPAR $\gamma$, which is a HIF target gene and essential in WAT browning [45-47].

Even though fructose is also required to develop liver injury on the HF-MCD diet, which contains sucrose [48], this diet additionally prevents hepatic VLDL export further compromising liver metabolism. This likely explains the lower degree of downregulation of hepatic lipid metabolism genes in the Hif-p $4 h-2^{g t / g t}$ mice on the HF-MCD diet compared with the HFHF diet.

NAFLD treatment is currently based on diet and exercise, while several therapeutics are being used with varying results. We show here that beneficial effects could be obtained with HIF-P4H-2 inhibition, as its genetic deficiency counteracted the symptoms of NAFLD. However, treatment with pan-HIF$\mathrm{P} 4 \mathrm{H}$ inhibitor was unable to reduce steatosis, as it demonstrated reduced ability to downregulate hepatic lipogenic gene expression in the HFHF diet and failure to significantly induce WAT browning in the HF-MCD diet. These data suggest that treatment of NAFLD by HIF-P4H inhibition should target only isoenzyme 2 . This is supported by previous studies that associate the knockout of all HIF-P4Hs with steatosis, while the presence of a single HIF-P4H-1 or HIF-P4H-3 allele minimizes steatosis [49]. In conclusion, our findings demonstrate important underlying mechanisms of HIF-P4H-2 interference involving organ crosstalk in the pathogenesis of NAFLD, which offers potential for developing HIF-P4H-2 inhibitors for its treatment.

Acknowledgments Open access funding provided by University of Oulu including Oulu University Hospital. We thank T. Aatsinki, E. Lehtimäki, and S. Moilanen for expert technical assistance.

Authors' contributions AL, JT, FD, RS, EYD, and PK performed the experiments and analyzed the data. KAM and $\mathrm{KHH}$ performed the home cage phenotyping. HG analyzed hepatic cholesterol metabolites. GW provided FG-4497. JM and PK generated the Hif-p4h-2 $2^{\text {gt/gt }}$ mice. AL and PK wrote the paper.

Funding information This study was supported by the Academy of Finland grants 266719 and 308009 (PK), and 296498 (JM), the Academy of Finland Center of Excellence 2012-2017 grant 251314 (JM), and grants from the S. Jusélius Foundation (PK and JM), the Finnish Cancer Organization (PK), and the Jane and Aatos Erkko Foundation (PK and JM).

\section{Compliance with ethical standards}

Conflict of interest GW is an employee and a shareholder of FibroGen, Inc., which develops HIF-P4H inhibitors as therapeutics. JM owns equity in the company, which supports research by JM.
Ethics statement All experiments were conducted according to the Finnish Act on Animal Experimentation (62/2006) and approved by the National Animal Experiment Board of Finland.

Open Access This article is licensed under a Creative Commons Attribution 4.0 International License, which permits use, sharing, adaptation, distribution and reproduction in any medium or format, as long as you give appropriate credit to the original author(s) and the source, provide a link to the Creative Commons licence, and indicate if changes were made. The images or other third party material in this article are included in the article's Creative Commons licence, unless indicated otherwise in a credit line to the material. If material is not included in the article's Creative Commons licence and your intended use is not permitted by statutory regulation or exceeds the permitted use, you will need to obtain permission directly from the copyright holder. To view a copy of this licence, visit http://creativecommons.org/licenses/by/4.0/.

\section{References}

1. Diehl AM, Day C (2017) Cause, pathogenesis, and treatment of nonalcoholic steatohepatitis. N Engl J Med 377:2063-2072

2. Asrani SK, Devarbhavi H, Eaton J, Kamath PS (2019) Burden of liver diseases in the world. J Hepatol 70:151-171

3. Asrih M, Jornayvaz FR (2014) Diets and nonalcoholic fatty liver disease: the good and the bad. Clin Nutr 33:186-190

4. Leoni S, Tovoli F, Napoli L, Serio I, Ferri S, Bolondi L (2018) Current guidelines for the management of non-alcoholic fatty liver disease: a systematic review with comparative analysis. World J Gastroenterol 24:3361-3373

5. Kaelin WG, Ratcliffe PJ (2008) Oxygen sensing by metazoans: the central role of the HIF hydroxylase pathway. Mol Cell 30:393-402

6. Koivunen P, Serpi R, Dimova EY (2016) Hypoxia-inducible factor prolyl 4-hydroxylase inhibition in cardiometabolic diseases. Pharmacol Res 114:265-273

7. Semenza GL (2012) Hypoxia-inducible factors in physiology and medicine. Cell 148:399-408

8. Berra E, Benizri E, Ginouves A, Volmat V, Roux D, Pouyssegur J (2003) HIF prolyl-hydroxylase 2 is the key oxygen sensor setting low steady-state levels of HIF-1alpha in normoxia. EMBO J 22: 4082-4090

9. Hirsilä M, Koivunen P, Günzler V, Kivirikko KI, Myllyharju J (2003) Characterization of the human prolyl 4-hydroxylases that modify the hypoxia-inducible factor. J Biol Chem 278:3077230780

10. Koivunen P, Kietzmann T (2018) Hypoxia-inducible factor prolyl 4-hydroxylases and metabolism. Trends Mol Med 24:1021-1035

11. Dhillon S (2019) Roxadustat: first global approval. Drugs

12. Matsuura H, Ichiki T, Inoue E, Nomura M, Miyazaki R, Hashimoto T, Ikeda J, Takayanagi R, Fong G, Sunagawa K (2013) Prolyl hydroxylase domain protein 2 plays a critical role in diet-induced obesity and glucose intolerance. Circulation 127:2078-2087

13. Marsch E, Demandt JAF, Theelen TL, Tullemans BME, Wouters K, Boon MR, van Dijk TH, Gijbels MJ, Dubois LJ, Meex SJR, Mazzone M, Hung G, Fisher EA, Biessen EA, Daemen MJ, Rensen PC, Carmeliet P, Groen AK, Sluimer JC (2016) Deficiency of the oxygen sensor prolyl hydroxylase 1 attenuates hypercholesterolaemia, atherosclerosis, and hyperglycaemia. Eur Heart J 37:2993-2997

14. Rahtu-Korpela L, Karsikas S, Horkko S, Blanco Sequeiros R, Lammentausta E, Makela KA, Herzig KH, Walkinshaw G, Kivirikko KI, Myllyharju J et al (2014) HIF prolyl 4hydroxylase-2 inhibition improves glucose and lipid 
metabolism and protects against obesity and metabolic dysfunction. Diabetes 63:3324-3333

15. Voss JD, Masuoka P, Webber BJ, Scher AI, Atkinson RL (2013) Association of elevation, urbanization and ambient temperature with obesity prevalence in the United States. Int J Obes 37:14071412

16. Woolcott OO, Ader M, Bergman RN (2015) Glucose homeostasis during short-term and prolonged exposure to high altitudes. Endocr Rev 36:149-173

17. Rahtu-Korpela L, Maatta J, Dimova EY, Horkko S, Gylling H, Walkinshaw G, Hakkola J, Kivirikko KI, Myllyharju J, Serpi R et al (2016) Hypoxia-inducible factor prolyl 4-hydroxylase-2 inhibition protects against development of atherosclerosis. Arterioscler Thromb Vasc Biol 36:608-617

18. Laitakari A, Huttunen R, Kuvaja P, Hannuksela P, Szabo Z, Heikkilä M, Kerkelä R, Myllyharju J, Dimova EY, Serpi R et al (2020) Systemic long-term inactivation of hypoxia-inducible factor prolyl 4-hydroxylase 2 ameliorates aging-induced changes in mice without affecting their life span. FASEB J

19. Laitakari A, Ollonen T, Kietzmann T, Walkinshaw G, Mennerich D, Izzi V, Haapasaari K, Myllyharju J, Serpi R, Dimova EY et al (2019) Systemic inactivation of hypoxia-inducible factor prolyl 4hydroxylase 2 in mice protects from alcohol-induced fatty liver disease. Redox Biol 22:101145

20. Ganz M, Bukong TN, Csak T, Saha B, Park J, Ambade A, Kodys K, Szabo G (2015) Progression of non-alcoholic steatosis to steatohepatitis and fibrosis parallels cumulative accumulation of danger signals that promote inflammation and liver tumors in a high fat-cholesterol-sugar diet model in mice. J Transl Med 13:193

21. Matsumoto M, Hada N, Sakamaki Y, Uno A, Shiga T, Tanaka C, Ito T, Katsume A, Sudoh M (2013) An improved mouse model that rapidly develops fibrosis in non-alcoholic steatohepatitis. Int J Exp Pathol 94:93-103

22. Caballero F, Fernandez A, Matias N, Martinez L, Fucho R, Elena M, Caballeria J, Morales A, Fernandez-Checa JC, Garcia-Ruiz C (2010) Specific contribution of methionine and choline in nutritional nonalcoholic steatohepatitis: impact on mitochondrial Sadenosyl-L-methionine and glutathione. J Biol Chem 285: $18528-18536$

23. Hyvarinen J, Hassinen IE, Sormunen R, Maki JM, Kivirikko KI, Koivunen P, Myllyharju J (2010) Hearts of hypoxia-inducible factor prolyl 4-hydroxylase-2 hypomorphic mice show protection against acute ischemia-reperfusion injury. J Biol Chem 285:13646-13657

24. Merry TL, Tran M, Stathopoulos M, Wiede F, Fam BC, Dodd GT, Clarke I, Watt MJ, Andrikopoulos S, Tiganis T (2014) High-fat-fed obese glutathione peroxidase 1-deficient mice exhibit defective insulin secretion but protection from hepatic steatosis and liver damage. Antioxid Redox Signal 20:2114-2129

25. Merry TL, Tran M, Dodd GT, Mangiafico SP, Wiede F, Kaur S, McLean CL, Andrikopoulos S, Tiganis T (2016) Hepatocyte glutathione peroxidase-1 deficiency improves hepatic glucose metabolism and decreases steatohepatitis in mice. Diabetologia 59: 2632-2644

26. Jang C, Hui S, Lu W, Cowan AJ, Morscher RJ, Lee G, Liu W, Tesz GJ, Birnbaum MJ, Rabinowitz JD (2018) The small intestine converts dietary fructose into glucose and organic acids. Cell Metab 27: 351-361.e3

27. Karsikas S, Myllymäki M, Heikkilä M, Sormunen R, Kivirikko KI, Myllyharju J, Serpi R, Koivunen P (2016) HIF-P4H-2 deficiency protects against skeletal muscle ischemia-reperfusion injury. $\mathrm{J}$ Mol Med 94:301-310

28. Jha P, Knopf A, Koefeler H, Mueller M, Lackner C, Hoefler G, Claudel T, Trauner M (2014) Role of adipose tissue in methionine-choline-deficient model of non-alcoholic steatohepatitis (NASH). Biochim Biophys Acta 1842:959-970
29. Lee YH, Kim SH, Kim SN, Kwon HJ, Kim JD, Oh JY, Jung YS (2016) Sex-specific metabolic interactions between liver and adipose tissue in MCD diet-induced non-alcoholic fatty liver disease. Oncotarget 7:46959-46971

30. Guilherme A, Virbasius JV, Puri V, Czech MP (2008) Adipocyte dysfunctions linking obesity to insulin resistance and type 2 diabetes. Nat Rev Mol Cell Biol 9:367-377

31. Miyazaki M, Dobrzyn A, Man WC, Chu K, Sampath H, Kim H, Ntambi JM (2004) Stearoyl-CoA desaturase 1 gene expression is necessary for fructose-mediated induction of lipogenic gene expression by sterol regulatory element-binding protein1c-dependent and -independent mechanisms. J Biol Chem 279: 25164-25171

32. Lim JS, Mietus-Snyder M, Valente A, Schwarz J, Lustig RH (2010) The role of fructose in the pathogenesis of NAFLD and the metabolic syndrome. Nat Rev Gastroenterol Hepatol 7: 251-264

33. Jensen T, Abdelmalek MF, Sullivan S, Nadeau KJ, Green M, Roncal C, Nakagawa T, Kuwabara M, Sato Y, Kang D, Tolan DR, Sanchez-Lozada LG, Rosen HR, Lanaspa MA, Diehl AM, Johnson RJ (2018) Fructose and sugar: a major mediator of non-alcoholic fatty liver disease. J Hepatol 68:1063-1075

34. Taniguchi CM, Finger EC, Krieg AJ, Wu C, Diep AN, LaGory EL, Wei K, McGinnis LM, Yuan J, Kuo CJ, Giaccia AJ (2013) Crosstalk between hypoxia and insulin signaling through Phd3 regulates hepatic glucose and lipid metabolism and ameliorates diabetes. Nat Med 19:1325-1330

35. Minamishima YA, Kaelin WG (2010) Reactivation of hepatic EPO synthesis in mice after PHD loss. Science 329:407

36. Morello E, Sutti S, Foglia B, Novo E, Cannito S, Bocca C, Rajsky M, Bruzzì S, Abate ML, Rosso C, Bozzola C, David E, Bugianesi E, Albano E, Parola M (2018) Hypoxia-inducible factor $2 \alpha$ drives nonalcoholic fatty liver progression by triggering hepatocyte release of histidine-rich glycoprotein. Hepatology 67:2196-2214

37. Rankin EB, Rha J, Selak MA, Unger TL, Keith B, Liu Q, Haase VH (2009) Hypoxia-inducible factor 2 regulates hepatic lipid metabolism. Mol Cell Biol 29:4527-4538

38. Kim WY, Safran M, Buckley MRM, Ebert BL, Glickman J, Bosenberg M, Regan M, Kaelin WG (2006) Failure to prolyl hydroxylate hypoxia-inducible factor alpha phenocopies VHL inactivation in vivo. EMBO J 25:4650-4662

39. Fuchs CD, Claudel T, Kumari P, Haemmerle G, Pollheimer MJ, Stojakovic T, Scharnagl H, Halilbasic E, Gumhold J, Silbert D, Koefeler H, Trauner M (2012) Absence of adipose triglyceride lipase protects from hepatic endoplasmic reticulum stress in mice. Hepatology 56:270-280

40. Schweiger M, Romauch M, Schreiber R, Grabner GF, Hütter S, Kotzbeck P, Benedikt P, Eichmann TO, Yamada S, Knittelfelder $O$ et al (2017) Pharmacological inhibition of adipose triglyceride lipase corrects high-fat diet-induced insulin resistance and hepatosteatosis in mice. Nat Commun 8:14859

41. Huang Y, Cohen JC, Hobbs HH (2011) Expression and characterization of a PNPLA3 protein isoform (I148M) associated with nonalcoholic fatty liver disease. J Biol Chem 286:37085-37093

42. Leung T, Nieto N (2013) CYP2E1 and oxidant stress in alcoholic and non-alcoholic fatty liver disease. J Hepatol 58:395-398

43. Gozal D, Gileles-Hillel A, Cortese R, Li Y, Almendros I, Qiao Z, Khalyfa AA, Andrade J, Khalyfa A (2017) Visceral white adipose tissue after chronic intermittent and sustained hypoxia in mice. Am J Respir Cell Mol Biol 56:477-487

44. van den Borst B, Schols AMWJ, de Theije C, Boots AW, Köhler SE, Goossens GH, Gosker HR (2013) Characterization of the inflammatory and metabolic profile of adipose tissue in a mouse model of chronic hypoxia. J Appl Physiol 114:1619-1628 
45. Krishnan J, Suter M, Windak R, Krebs T, Felley A, Montessuit C, Tokarska-Schlattner M, Aasum E, Bogdanova A, Perriard E, Perriard JC, Larsen T, Pedrazzini T, Krek W (2009) Activation of a HIF1alpha-PPARgamma axis underlies the integration of glycolytic and lipid anabolic pathways in pathologic cardiac hypertrophy. Cell Metab 9:512-524

46. Vernochet C, Peres SB, Davis KE, McDonald ME, Qiang L, Wang H, Scherer PE, Farmer SR (2009) C/EBPalpha and the corepressors $\mathrm{CtBP} 1$ and $\mathrm{CtBP} 2$ regulate repression of select visceral white adipose genes during induction of the brown phenotype in white adipocytes by peroxisome proliferator-activated receptor gamma agonists. Mol Cell Biol 29:4714-4728
47. Ohno H, Shinoda K, Spiegelman BM, Kajimura S (2012) PPAR $\gamma$ agonists induce a white-to-brown fat conversion through stabilization of PRDM16 protein. Cell Metab 15:395-404

48. Pickens MK, Yan JS, Ng RK, Ogata H, Grenert JP, Beysen C, Turner SM, Maher JJ (2009) Dietary sucrose is essential to the development of liver injury in the methionine-choline-deficient model of steatohepatitis. J Lipid Res 50:2072-2082

49. Duan L, Takeda K, Fong G (2014) Hematological, hepatic, and retinal phenotypes in mice deficient for prolyl hydroxylase domain proteins in the liver. Am J Pathol 184:1240-1250

Publisher's note Springer Nature remains neutral with regard to jurisdictional claims in published maps and institutional affiliations. 